\title{
LA INTERPRETACIÓN DEL ART. 47 CDFUE COMO EXPRESIÓN DE LA LABOR HERMENÉUTICA DEL TRIBUNAL DE LUXEMBURGO EN LA CONSTRUCCIÓN DE UN ESTÁNDAR EUROPEO DE PROTECCIÓN DE LOS DERECHOS*
}

\author{
CIRO MILIONE \\ Profesor Titular (A) de Derecho Constitucional \\ Universidad de Córdoba
}

\begin{abstract}
SUMARIO
I. La Unión Europea ante el reto de los derechos fundamentales y la Carta de Niza tras 16 años desde su aprobación. II. El Capítulo VI «Justicia» de la CDFUE. III. Conclusiones: el alcance de la Carta tras las SSTJ de 26 de febrero de 2013, asuntos C-617/10 y C-399/11.
\end{abstract}

\section{PREMISA: LA UE ANTE EL RETO DE LOS DERECHOS FUNDAMENTALES Y LA CARTA DE NIZA TRAS 16 AÑOS DESDE SU APROBACIÓN.}

Volviendo nuestra mirada a los últimos veinte años de vida de la Unión Europea, podemos percibir el reflejo de una fase de inflexión de ese proyecto común. Las etapas de este lento proceso involutivo son bien conocidas y arrancan del intento frustrado de dotar a nuestra unión política de un texto fundacional que naufraga inexorablemente en el año 2004, ante la frustración de una parte de la ciudadanía europea llamada a ratificar con su voto un texto críptico e inexplicablemente avaro en materia de principios y derechos.

* El presente estudio se enmarca en el ámbito del proyecto $\mathrm{I}+\mathrm{D}$ «Contruyendo un estándar común de protección de los derechos fundamentales en la Unión Europea» (DER 2013-41303-P, Subprograma de proyectos de investigación fundamental no orientada, convocatoria del año 2013 del Ministerio de Economía y Competitividad, línea de Excelencia). Quisiera agradecer el Prof. Miguel J. Agudo Zamora por sus inestimables aportaciones que enriquecen ahora este trabajo y por su amable labor de revisión. Cualquier error, omisión o imprecisión es exclusivamente imputable al autor. 
El largo periodo de desaceleración de la economía global que ha seguido a los hechos ligados a la Constitución Europea y, sobre todo, la gestión política de la crisis social, consecuencia de dicha desaceleración, han servido para reafirmar en la opinión pública europea el convencimiento de que nuestro modelo de Unión es extremadamente lento e ineficaz a la hora de compatibilizar - y si cabe, anteponer- las demandas de libertad y derechos de la ciudadanía a las lógicas del mercado. Ese «pecado original» imputado al proyecto de unificación europea desde sus principios, el de haber nacido bajo los auspicios de intereses principalmente económicos e incidentalmente sociales, parece no haber sido borrado todavía.

Sin embargo, estos mismos 20 años nos devuelven también imágenes de otra índole, instantes en los que Europa actuó más coherentemente con sus principios fundacionales, inspirados en los valores de respeto de la dignidad humana, libertad, democracia, igualdad, Estado de Derecho y derechos humanos. Entre otros, destacan dos momentos claves para una afirmación más efectiva de esos valores en el marco europeo: la aprobación de la Carta de los Derechos Fundamentales de la Unión Europea (CDFUE), proclamada solemnemente en Niza el 7 de diciembre de 2000, y la entrada en vigor del Tratado de Lisboa (de diciembre 2007) el 1 de enero del año 2009 que vino a otorgar a la Carta, hasta entonces mera declaración de principios, igual valor jurídico que el Tratado de la Unión Europea (TUE) y el Tratado de Funcionamiento de la Unión Europea (TFUE).

A partir de esa fecha la Carta ha pasado a constituir objeto de la jurisdicción del Tribunal de Justicia de la Unión Europea (TJUE) contribuyendo este último, a través de una intensa labor interpretativa, a la definición del alcance de sus preceptos.

Como señala López Martin, el papel de los órganos jurisdiccionales ha sido clave en el proceso de integración europeo, un factor de arraigo y de desarrollo de la organización política supranacional. A los jueces se debe la capacidad de dar eficacia y efectividad a los principios y normas comunitarias y al TJUE, en particular, el haber «contribuido a asentar el sistema jurídico de las Comunidades» ${ }^{\circledR}$.

En este estudio hemos decidido centrarnos en un precepto particular de la CDFUE, el art. 47 por el que se proclaman algunos principios claves de la tutela judicial efectiva. La razón de esta elección descansa en la constatación de que dichos principios, además de formar parte de un conjunto de garantías

1 Lopez Martin, A. G., «Capítulo 13. Derecho a la tutela judicial efectiva y a un juez imparcial», en Beneyto Perez, J. M., (Dir), Maillo Gonzalez-Oruz, J. y Becerril Atienza, B. (Coord.), Tratado de Derecho y de Políticas de la Unión Europea, Tomo II, Derechos Fundamentales, Aranzadi Thomson-Reuters, 2009, p. 795, que además recuerda «es patente el lugar central que ocupan las exigencias de la tutela judicial efectiva en la protección de dichos derechos (humanos y libertades individuales). Sin juicio equitativo, sin tutela judicial efectiva, mal puede hablarse del respeto de los derechos humanos y de un verdadero sistema democrático». En este mismo sentido, Pastor Ridruejo, J. A., «La tutela judicial efectiva en la jurisprudencia del Tribunal Europeo de Derechos Humanos: Temas escogidos», en MARiño Menendez, F. (Ed.), El Derecho internacional en los albores del siglo XXI: Homenaje al profesor Juan Manuel Castro-Rial Canosa, Madrid, Trotta, 2002, p. 521. 
democráticas esenciales ${ }^{2}$, desarrollan una función determinante en la tutela y protección de las demás situaciones jurídico-subjetivas reconocidas en la Carta.

Y, en efecto, la proclamación de cualquier derecho, fuere cual fuere su contenido sustancial, sin la previsión de instrumentos jurídicos dirigidos a asegurar su efectividad, vacía de todo sentido ese reconocimiento y hace de ese derecho una mera declaración de principios, cuyo respeto descansa en la buena voluntad de los poderes públicos.

Además, desde un punto de vista meramente estadístico, hay que considerar que, con diferencia, el art. 47 es el precepto de la Carta más analizado, y, por lo tanto, más permanente e ininterrumpidamente interpretado, por el Tribunal de Luxemburgo ${ }^{3}$.

Por lo tanto, decenas de resoluciones del TJUE han intentado establecer con precisión sus contornos, y esta labor hermenéutica —como en parte veremostodavía sigue produciéndose.

\section{EL CAPÍTULO VI «JUSTICIA» DE LA CARTA DE LOS DERECHOS FUNDAMENTALES DE LA UNIÓN EUROPEA (CDFUE)}

La CDFUE dedica su Capítulo VI al tema de la Justicia, desarrollando en cuatro distintos preceptos (arts. 47-50) lo que algunos consideran como los principios básicos del Derecho procesal de la Unión ${ }^{4}$.

Más concretamente, el art. 47 CDFUE reconoce el derecho a la tutela judicial efectiva para toda persona cuyos derechos y libertades garantizados por el

2 Consideraciones que, mutatis mutandis, Soyer, J. C. y De Salvia, M. («Article 6», en Petitti, L. E., Decaux, E., Imbert, P. H., (Coord.), La Convention Européenne des Droits de l'Homme. Commentaire article par article, Ed. Economica, París, 1995, pp. 240 y 241) han llevado a cabo respecto a un precepto, cuyo contenido esencial coincide con el art. 47 CDFUE: el art. 6 del Convenio Europeo de Derechos Humanos (CEDH).

3 Una consulta de la base de datos del TJUE (disponible en línea en http:// http://curia.europa.eu/) lo pone en evidencia: al 13 de mayo de 2016, el precepto más interpretado por esa Corte es el art. 47 con 169 resoluciones, seguido por el art. 51 («Ámbito de aplicación de la Carta») con 85 y por el art. 21 («No discriminación») con 56. Las mismas consideraciones valen por la norma correspondiente al art. 47 CDFUE en el CEDH: el art. 6. El mismo Tribunal de Estrasburgo indica en su publicación Overview 1959-2014 (disponible en línea en http://www. echr.coe.int/Documents/Overview_19592014_ENG.pdf, p. 5, fecha de consultación 19/01/2016) que «More than $42 \%$ of the violations found by the Court concern Article 6 of the Convention, whether on account of the fairness or the length of the proceedings.» En este sentido, vd. Russo, C., QuAINI, P. M., La Convenzione Europea dei diritti dell'uomo e la giurisprudenza della Corte di Strasburgo, Milano, 2000, pp. 86-98. Cfr. Chiavario, M., «Diritto a un processo equo», en BARtole, S., Conforti, B., Raimondi, G., (Coord.), Commentario della Convenzione Europea per la tutela dei diritti dell'uomo e delle libertà fondamentali, Ed. Cedam, Milano, 2001, pp. 153-248.

4 En este sentido, FagGiani, V., «El derecho a la tutela judicial efectiva y a un proceso con todas las garantías en la Carta de los Derechos Fundamentales de la Unión Europea», en Revista General de Derecho Europeo, n. ${ }^{\circ} 33$, 2014, pp. 2 y 4, citando CoppetTA, M. ${ }^{a}$ G., «Verso un proceso penale europeo?», en CoppetTA, M. ${ }^{a}$ G., (Coord.), Profili del processo penale nella Costituzione europea, Giappichelli, Universitá degli Studi di Urbino «Carlo Bo». Facoltá di Scienze Politiche. Istituto Giuridico, 2005, p. 12, para hacer referencia al "núcleo de un derecho constitucional procesal de la Unión Europea.» 
ordenamiento jurídico de la Unión hayan sido objeto de violación. Asimismo, la norma reconoce el derecho a un proceso público, al plazo razonable, a un juez independiente, imparcial y establecido previamente por la ley, a la representación legal y a la asistencia jurídica gratuita.

El art. 48 CDFUE, por su parte, introduce el derecho a la presunción de inocencia y a los derechos de defensa.

El art. 49 CDFUE hace referencia al principio de legalidad, por el que nadie podrá ser condenado por una acción u omisión que, en el momento en el que haya sido cometida, no constituya una infracción según el Derecho nacional o el Derecho internacional. Asimismo, la norma establece que no podrá ser impuesta una pena más grave que la aplicable en el momento en que la infracción haya sido cometida. En el tercer párrafo de dicho precepto se prescribe que la intensidad de las penas no deberá ser desproporcionada en relación con la infracción.

Por último, el art. 50 CDFUE consagra el principio del ne bis in idem que viene a actuar, además, como mecanismo de coordinación entre jurisdicciones nacionales. Así, el precepto establece que nadie podrá ser acusado o condenado penalmente por una infracción respecto de la cual ya haya sido absuelto o condenado en la Unión mediante sentencia penal firme conforme a la ley.

La inclusión en la CDFUE de un capítulo dedicado exclusivamente a la Justicia viene a reafirmar una de las razones de ser de este Tratado: reforzar la protección de los derechos fundamentales en el contexto político de la Unión.

Todo ello hace comprensible que el legislador europeo, a través de los arts. 47-50 CDFUE, haya querido dotar su propio sistema jurisdiccional de instrumentos capaces de garantizar aquel conjunto de valores y principios que constituyen la base de la Unión.

Sin embargo, el Capítulo VI no introduce nuevas garantías procesales ajenas al patrimonio de tradiciones constitucionales de los Estados miembros, o desconocidas por el CEDH o por la jurisprudencia del Tribunal Europeo de Derechos Humanos (TEDH) o del TJUE. Al igual que para los cinco capítulos anteriores, la Carta, en lugar que renovar el acervo de situaciones jurídico-subjetivas, viene a sistematizar, refundir y a dar «mayor proyección» a los derechos políticos, civiles, económicos y sociales de toda persona residente en el territorio de la Unión. Como recuerda SOBRINO HEREDIA «la Carta reproduce y sistematiza un derecho positivo ya existente, pero dotándolo de una actualización ineludible derivada de la necesidad de reforzar la protección de los derechos fundamentales a tenor de la evolución de la sociedad, del progreso social y de los avances científicos y tecnológicos. ${ }^{5}$

5 En este sentido, Sobrino Heredia, J. M., «Preámbulo», en Mangas Martin, A., (Dir.), Carta de los Derechos Fundamentales de la Unión Europea. Comentario artículo por artículo, Fundación BBVA, 2008, p. 99. 


\section{El alcance del derecho a la tutela judicial efectiva en el primer párrafo del art. 47 CDFUE}

Investigar, de manera pormenorizada, el alcance de cada vertiente y de cada una de las garantías consagradas por el Capítulo VI de la Carta de Niza excedería inevitablemente los límites de este trabajo. Por ello es preciso acotar nuestra atención a lo que puede considerarse como el núcleo esencial del derecho a la tutela judicial efectiva en la CDFUE, es decir al art. 47. En efecto, no sería correcto poner sobre un mismo plano los principios recogidos en dicha norma con los que introducen los otros tres artículos pues, como señala MIGUEZ MACHO, únicamente el art. 47 CDFUE «se refiere a derechos fundamentales relacionados con la administración de la justicia en general; el resto recogen garantías frente al ejercicio de jus punendi por los Poderes públicos, y garantías que no tienen carácter procesal solamente, sino también sustantivo.» ${ }^{6}$

La forma más eficaz de esclarecer el contenido del art. 47 CDFUE nos conduce, en primer lugar, a intentar recabar su «interpretación auténtica» investigando las intenciones de los actores políticos-institucionales que determinaron su contenido normativo, para reconstruir cuáles fueron los principios inspiradores y cuáles las determinaciones sustanciales de este precepto.

Para todo ello, podemos hacer referencia a las «Explicaciones sobre las Cartas» transcritas por el Praesidium ${ }^{7}$, a sabiendas de que su trascendencia e importancia se limitan al ámbito meramente hermenéutico ${ }^{8}$, careciendo las mismas de todo valor jurídico. Asimismo, es imprescindible analizar el corpus jurisprudencial del TJUE, fruto de la labor interpretativa de esta suprema instancia.

El primer párrafo del art. 47 CDFUE halla su fundamento en el art. 13 $\mathrm{CEDH}$ que prescribe el derecho a un recurso efectivo ante una instancia nacional.

Sin embargo, el Praesidium aclara que el alcance de la protección garantizada por la Carta es más extenso, pues exige que dicho recurso se celebre ante un órgano jurisdiccional. Según argumentan las explicaciones, este derecho constituye un

6 Miguez Macho, L., «Los derechos de justicia en la Carta de los Derechos Fundamentales de la Unión Europea», Ruiz Miguel, C., Estudios sobre la Carta de los Derechos Fundamentales de la Unión Europea, Universidade de Santiago de Compostela, 2004, pp. 189-190.

7 Diario Oficial de la Unión Europea C 303/17-14.12.2007, también disponibles en European Unión Agency for Fundamental Rights [en línea], <http://fra.europa.eu/es/charterpedia/article/47-derecho-la-tutela-judicial-efectiva-y-un-juez-imparcial > (Consulta: 14-01-2016).

8 En este sentido, cabe recordar el contenido del tercer apartado del art. 6.1 del Tratado de la Unión Europea (TUE), por el que «Los derechos, libertades y principios enunciados en la Carta se interpretarán con arreglo a las disposiciones generales del título VII de la Carta por las que se rige su interpretación y aplicación y teniendo debidamente en cuenta las explicaciones a que se hace referencia en la Carta, que indican las fuentes de dichas disposiciones. "

Al mismo modo, el art. 52.7 CDFUE otorga a las Explicaciones el valor de criterios hermenéuticos, estableciendo que deberán ser «tenidas debidamente en cuenta por los órganos jurisdiccionales de la Unión y de los Estados miembros». 
principio general del Derecho de la Unión ${ }^{9}$, razón por la que «el artículo 47 se aplica respecto de las instituciones de la Unión y de los Estados miembros cuando aplican el Derecho de la Unión, para todos los derechos que garantiza el Derecho de la Unión.»

No obstante, las explicaciones ponen de relieve que la referencia a este principio no tiene por finalidad modificar el sistema de control jurisdiccional establecido en los Tratados ni, en particular, las normas relativas a la admisibilidad de los recursos interpuestos directamente ante el Tribunal de Justicia de la Unión Europea.

El primer párrafo del art. 47 CDFUE se fundamenta — como recuerda Lopez Escudero $^{10}$ - en la constatación de que la aplicación del Derecho de la Unión es descentralizada. En efectos, compete a los jueces nacionales conocer de las causas que traen su origen de este sistema normativo, siendo el ámbito de competencia reservado al Tribunal de Justicia relativamente limitado. Por ello, podemos entender que dicho precepto se encuentre estrechamente relacionado con el art. 19.1 TUE ${ }^{11}$, por el que los Estados miembros deben establecer vías de recurso necesarias para garantizar la tutela judicial efectiva en los ámbitos cubiertos por el Derecho de la Unión ${ }^{12}$.

Este principio ha sido además enfatizado por el Tribunal de Justicia en la STJ de 19 de junio de 1990, asunto C-213, al afirmar que «corresponde a los órganos jurisdiccionales nacionales, en virtud del principio de cooperación establecido por el

9 Vd. Sentencia del Tribunal de Justicia (STJ) de 15 de mayo de 1986, asunto 222/84, donde se recuerda que «El control jurisdiccional [...] es la expresión de un principio general del Derecho que es básico en las tradiciones constitucionales comunes a los Estados miembros. Este principio está igualmente consagrado por los artículos 6 y 13 del Convenio Europeo para la protección de los Derechos Humanos y de las Libertades Fundamentales, de 4 de noviembre de 1950. Como ha sido reconocido en la declaración común del Parlamento, del Consejo y de la Comisión, de 5 de abril de 1977 (DO C 103, p. 1), y por la jurisprudencia del Tribunal de Justicia, conviene tener en cuenta, en el marco del Derecho comunitario, los principios en los que se inspira dicho Convenio»; asimismo, véase la STJ de 15 de octubre de 1987, asunto 222/86, y la STJ de 3 de diciembre de 1992, asunto C-97/91.

10 Lopez Escudero, M., «Artículo 47. Derecho a la tutela judicial efectiva y a un juez imparcial», en Mangas Martin, A., (Dir.), Carta..., ob. cit., pp. 742-743.

11 Introducido por el art.1.20 del Tratado de Lisboa por el que se modifican el Tratado de la Unión Europea y el Tratado constitutivo de la Comunidad Europea (DOUEC, n. ${ }^{\circ} 306$, de 17 de diciembre de 2007). Algo que ha suscitado las críticas de una parte de la doctrina por la ausencia en este precepto de cualquier referencia al papel del juez nacional como sujeto plenamente legitimado a juzgar cuestiones de Derecho de la Unión que se planteen en el desarrollo de sus funciones jurisdiccionales, con la única excepción de las cuestiones prejudiciales cuya resolución compete al Tribunal de Justicia. En este sentido, vd. Informe del Grupo de Reflexión sobre el futuro del sistema judicial de las Comunidades Europeas, enero 2000; Alfonso DAstis, D. y Gijs De VRIEs, D., «Propuestas para garantizar mayor eficiencia y eficacia en los métodos de trabajo del Tribunal de Justicia y del Tribunal de Primera Instancia», CONTRIB 277, CONV 620/03, p. 5 , que afirman «Uno de los rasgos principales del sistema jurídico de la UE es que su respeto y ejecución está garantizado por los tribunales nacionales, que, por lo tanto, actúan como parte de «la estructura jurisdiccional de la UE». Todo el procedimiento de las decisiones prejudiciales por parte del TJE o del TPI se basa en este entendimiento. Parece apropiado que un elemento tan importante de la UE como «comunidad de derecho» sea reconocido explícitamente en el futuro Tratado»; estas últimas referencias doctrinales citadas además por ALONSO Garcia, R., «Lisboa y el Tribunal de Justicia de la Unión Europea», en Papeles de Derecho Europeo e Integración Regional. Working Papers on European Law and Regional Integration, n. ${ }^{\circ}$ 1, 2010, p. 4.

12 Asimismo se ha pronunciado el Tribunal de Luxemburgo con la STJ de 25 de julio de 2002, asunto C-50/00, estableciendo que «corresponde a los Estados miembros prever un sistema de vías de recurso y de procedimientos que permita garantizar el respeto a la tutela judicial efectiva». 
artículo 5 del Tratado, proporcionar la protección jurídica que se deriva para los justiciables del efecto directo de las disposiciones del Derecho comunitario».

Por estas mismas razones, es posible enlazar el contenido del primer párrafo del art. 47 CDFUE con el principio de cooperación leal establecido por el art. 4.3 del TUE (anteriormente, art. 10 del Tratado de la Comunidad Europea, TCE) en virtud del cual se afirma, entre otros, el deber de los Estados miembros de adoptar todas las medidas generales y particulares para asegurar un apropiado cumplimiento de las obligaciones derivadas de los Tratados o resultantes de los actos de las instituciones de la Unión.

\section{El derecho a un proceso justo y las demás garantías procesales previstas por el segundo párrafo del art. 47 CDFUE}

El segundo párrafo del art. 47 CDFUE constituye una norma con un contenido particularmente amplio y complejo, pues consagra un abanico de garantías (derecho de acceso a los tribunales, derecho a un proceso justo, derecho a un proceso público, a un juez imparcial, independiente y establecido por la ley, derecho al plazo razonable, derecho a la representación legal, etc.) que ya venían contempladas en el art. 6 CEDH.

El TJUE ha puesto en evidencia, en repetidas ocasiones, que el derecho de acceso a los tribunales — primordial en la perspectiva de la tutela judicial efectiva- constituye uno de los elementos esenciales del Estado de Derecho en los que se inspira la Unión. Así lo vemos claramente en distintas resoluciones del Tribunal de Luxemburgo que introducen el principio del «efecto directo» ${ }^{13}$ y el principio de «supremacía del Derecho de la Unión» ${ }^{14}$. Asimismo, particularmente relevante es la STJ 19 de noviembre de 1991, asuntos C-6 y C-9/90, que introduce el concepto de «responsabilidad del Estado miembro», al recordar el Tribunal que «el Tratado CEE ha creado un ordenamiento jurídico propio, integrado en los sistemas jurídicos de los Estados miembros y que se impone a sus órganos jurisdiccionales, cuyos sujetos no son sólo los Estados miembros, sino también sus nacionales y que, al igual que impone cargas a los particulares, el Derecho comunitario también genera derechos que entran a formar parte de su patrimonio jurídico [...por lo que.... incumbe a los órganos jurisdiccionales nacionales encargados de aplicar, en el marco de sus competencias, las disposiciones de Derecho comunitario, garantizar la plena eficacia de tales normas y proteger los derechos que confieren a los particulares.»

13 Vd., entre otras, la STJ de 5 de febrero de 1963, asunto 26/62, con la que el Tribunal afirma que "el artículo 12 del Tratado (CEE) tiene un efecto directo en Derecho interno, en el sentido de que los nacionales de los Estados miembros puedan invocar, basándose en este artículo, derechos que el Juez nacional deba proteger».

14 Vd., entre otras, la STJ de 15 de julio de 1964, asunto 6/64, por la que «la primacía del Derecho comunitario está confirmada por el artículo 189, a cuyo tenor los Reglamentos tienen fuerza «obligatoria» y son "directamente aplicables en cada Estado miembro» que esta disposición, que [...] carecería de alcance si un Estado pudiera unilateralmente destruir sus efectos mediante un acto legislativo oponible a las normas comunitarias [...] que del conjunto de estos elementos se desprende que al Derecho creado por el Tratado [...] no se puede oponer, en razón de su específica naturaleza original una norma interna, cualquiera que sea ésta, ante los órganos jurisdiccionales, sin que al mismo tiempo aquél pierda su carácter comunitario y se ponga en tela de juicio la base jurídica misma de la Comunidad». 
Con la STJ de 16 de diciembre 1976, asunto C-33/76, la suprema instancia europea intensifica el alcance del derecho de acceso a los tribunales introduciendo, además, dos principios básicos para una efectiva garantía de la eficacia del Derecho de la Unión: el principio de equivalencia y el principio de efectividad.

En ese contexto, el Tribunal de Luxemburgo reconoce que «a falta de normativa comunitaria en la materia, corresponde al ordenamiento jurídico interno de cada Estado miembro designar los órganos jurisdiccionales competentes y regular las modalidades procesales de los recursos en vía jurisdiccional que hayan de procurar la salvaguarda de los derechos que en favor de los justiciables genera el efecto directo del Derecho comunitario", estableciendo que dichas normas en ningún caso pueden ser menos favorables que las correspondientes a recursos similares de carácter interno («principio de equivalencia») ni que hagan imposible en la práctica, o excesivamente difícil, el ejercicio de tales recursos («principio de efectividad») ${ }^{15}$.

Por su parte, el Praesidium, que también detecta en el segundo párrafo del art. $47 \mathrm{CDFUE}$ numerosas coincidencias con el primer párrafo del art. $6 \mathrm{CEDH}$, aclara que «en el Derecho de la Unión, el derecho a un tribunal no se aplica únicamente a litigios relativos a derechos y obligaciones de carácter civil».

Así lo pone de manifiesto el mismo Tribunal de Justicia con la STJ de 23 de abril de 1986, asunto 294/83, al afirmar que «la Comunidad Económica Europea es una comunidad de Derecho, en la medida en que ni sus Estados miembros ni sus instituciones pueden sustraerse al control de la conformidad de sus actos con la carta constitucional fundamental que constituye el Tratado [...] Cuando la aplicación administrativa de estos actos compete a las instituciones comunitarias, las personas físicas y jurídicas pueden interponer un recurso directo ante el Tribunal de Justicia contra los actos de aplicación de que sean destinatarias o que les afecten directa e individualmente e invocar, en apoyo de este recurso, la ilegalidad del acto general de base. Cuando su ejecución sea competencia de las instancias nacionales, aquéllas pueden alegar la invalidez de los actos de alcance general ante los órganos jurisdiccionales nacionales e inducirles a consultar al Tribunal de Justicia a este respecto mediante las cuestiones prejudiciales.»

No obstante, el catalogo de garantías previsto por dicho precepto goza de un alcance general que trasciende la actividad jurisdiccional referida meramente al ámbito civil o penal.

Al principio de este epígrafe dedicado al segundo párrafo del art. 47 CDFUE señalábamos que este precepto no se limita a establecer el derecho de acceso a los tribunales, sino que recoge un catálogo muy amplio de principios inherentes a la

15 Vd., en este mismo sentido, las SsTJ de 16 de mayo 2000, asunto C-78/98; de 9 de marzo de 1978 , C-106/77; de 19 de junio de 1990, C-213/89; de 14 de diciembre de 1995, C-430/93 y C-312/93; de 5 de octubre de 2006, C-368/04; de 20 de septiembre de 1990, C-5/89. Sobre dichos principios, véase además el Informe del Consejo de Estado sobre la inserción del Derecho Europeo en el ordenamiento español, E 1/2007, de 14 de febrero de 2008. Asimismo, Roldan Barbero, J., «La Carta de los Derechos Fundamentales de la UE: su estatuto constitucional», en Revista de Derecho Comunitario Europeo, 2003, n. ${ }^{\circ} 16$, pp. 943-991; y LopeZ EsCudero, M., «Artículo 47...», ob. cit., pp. 744-745. 
tutela judicial efectiva. Esto es particularmente cierto respecto de una serie de garantías - el derecho a un plazo razonable, el derecho al juez natural, el derecho a la imparcialidad judicial, el derecho a un intérprete, el derecho a la motivación de los actos judiciales, el derecho a la asistencia letrada, etc.- que han sido ampliamente interpretadas por el Tribunal de Justicia.

En primer lugar, en relación con el derecho a un juez natural, cabe señalar entre todas, la STJ de 13 de diciembre de 2012, asunto T-199/11 P. En esta resolución el Tribunal de Luxemburgo incorpora criterios interpretativos del TEDH (Sentencia del 22 de junio de 2000, caso Coëme y otros c. Bélgica; Sentencia de 20 de julio de 2006, caso Sokurenko y Strygun v. Ucrania) para afirmar que el concepto de «juez natural» atañe al órgano judicial cuya composición y competencia hayan sido previamente establecidas por la ley, como medida para «garantizar la independencia del Poder Judicial sobre el Ejecutivo». Asimismo, el TJUE aclara que este requisito no impide que dichos órganos puedan interpretar libremente las normas que regulan su organización y funcionamiento. Por esta razón, esta misma instancia desestima el recurso de una parte que había considerado violado su derecho a la tutela judicial efectiva sobre la base de la reasignación de su caso a una sala del Tribunal de la Función Pública con una composición distinta a la original ${ }^{16}$.

La misma STJ de 13 de diciembre de 2012, asunto T-199/11 P, adquiere importancia también en relación con el derecho a la imparcialidad judicial. Al respecto, el Tribunal de Luxemburgo define como «piedra angular del derecho a un proceso justo» la existencia de garantías relativas a la composición de la Corte, atribuyendo al juez de la Unión el deber de velar por el estricto cumplimiento de este principio sobre todo cuando se haya invocado la violación de ese derecho y la disputa en este punto no parezca manifiestamente infundada. A continuación, el Tribunal de Justicia señala que el requisito de la imparcialidad atañe a dos aspectos distintos: subjetivo y objetivo. Desde la primera perspectiva, es necesario que ningún miembro del órgano judicial muestre parcialidad o delate la existencia de prejuicios personales. Este tipo de imparcialidad se considera presunta hasta prueba de lo contrario y dicha presunción no puede ser derrotada sobre la base de meras suposiciones, sospechas o impresiones carentes de prueba. En relación a la parcialidad objetiva, el Tribunal de Luxemburgo se limita a indicar que todo tribunal debe ofrecer garantías suficientes para descartar a este respecto cualquier duda legítima ${ }^{17}$.

16 El TJUE además alega que, sobre la base de una asentada doctrina (Sentencia de 15 de octubre de 2002, asuntos C-238/99 P, C-244/99 P, C-245/99 P, C-247/99 P, C-250/99 P a C-252/99 P y C-254/99 P; y Sentendia de 2 de octubre de 2003, asunto C-182/99 P), no existe el derecho de la parte a que la composición del tribunal encargado de su causa no varíe durante todo el tiempo del procedimiento.

17 En este mismo sentido, vd. STJ de 1 de julio de 2008, C-341/06 P y C-342/06 P. El TJUE, en realidad, sobre este punto hace suya la doctrina del TEDH. Señalamos entre todas las SSTEDH de 17 de enero de 1970, caso Delcourt c. Bélgica; de 30 de octubre de 1991, caso Borgers c. Bélgica; de 1 de octubre de 1992, caso Piersack. c. Bélgica. Cfr. Milione, C., El derecho..., ob. cit., pp. 88-100. 
Cabe señalar, por último, que en numerosas ocasiones el TJUE ha recordado que el principio de imparcialidad no se aplica como tal a la Comisión Europea, por carecer dicha institución de la naturaleza de tribunal a la luz del art. 47 CDFUE y del art. $6 \mathrm{CEDH}^{18}$. Sin embargo, en la STJ de 27 de junio de 2012, asunto T-372/10, después de haber recordado este mismo concepto (apartado n. ${ }^{\circ}$ 57), el Tribunal de Luxemburgo señala que en el marco de procedimientos administrativos, como los concernientes al art. 101 (legislación antitrust) del TFUE, la Comisión debe ciertamente respetar, a lo largo de los mismos, los principios generales del Derecho de la Unión entre los que se encuentra el derecho a un proceso equitativo. No obstante, el TJUE concluye afirmando que «el becho de que la Comisión, órgano administrativo, ejerza a la vez las funciones de instrucción y de sanción de las infracciones del artículo 101 TFUE no constituye un incumplimiento de esa exigencia de imparcialidad, toda vez que sus decisiones están sometidas al control del juez de la Unión. ${ }^{19}$

Siempre en materia de legislación antitrust, una resolución del Tribunal de Luxemburgo sirve para aclarar el alcance del derecho a los medios de prueba. La referencia es a la STJ de 25 de enero de 2007, asunto C-411/04 P, con la que la suprema instancia europea adopta las conclusiones del Abogado General L.A. Geelhoed (de 12 de septiembre de 2006) en virtud de las cuales, en el Derecho comunitario de la competencia, la aportación de las pruebas debe centrarse en documentos, con la condición de que el juez encargado del procedimiento debe velar rigurosamente por la confidencialidad de las informaciones en ellos contenidas, para no frustrar los intereses legítimos de las empresas demandadas. Por todo ello, en dicha materia particularmente sensible, el TJUE declara que no puede ser de aplicación la doctrina del TEDH que niega la admisibilidad de medios de prueba documentales proporcionados por terceros cuyo anonimato deba garantizarse. En palabras del mismo Tribunal de Luxemburgo «en asuntos del Derecho comunitario de la competencia la prueba testifical sólo desempeña un papel secundario, mientras que los documentos escritos ocupan un lugar central [...] en estas circunstancias no cabe interpretar el principio de que toda persona tiene derecho a un proceso equitativo en el sentido de que los documentos que contengan pruebas de cargo han de ser descartados automáticamente como medio de prueba cuando ciertos datos deben permanecer confidenciales. Esta confidencialidad puede aplicarse también a la identidad de los autores de los documentos y de las personas que los hayan remitido a la Comisión».

En relación con el derecho a un plazo razonable, el Tribunal de Luxemburgo subraya en la Sentencia de 27 de junio de 2012, asunto T-372/10, que esta garantía constituye un principio general del Derecho de la Unión consagrado en el

18 STJ de 29 de octubre de 1980, asuntos de 209/78 a 215/78 y 218/78; Sentencias del Tribunal General de 14 de mayo de 1998, asuntos T-348/94.

19 En este mismo sentido, SsTJ de 11 de marzo de 1999, asunto T-156/94; de 14 de mayo de 1998, asunto T-348/94. 
segundo párrafo del art. 47 CDFUE, que además concierne y vincula a la misma Comisión cuando esta actúe en el marco de sus procedimientos administrativos ${ }^{20}$. Para apreciar la razonable duración de un proceso, el Tribunal señala la necesidad de examinar las circunstancias propias de cada asunto y, en particular, del contexto de éste, de las diferentes fases del procedimiento seguido, de la complejidad del asunto y de su trascendencia para las diferentes partes interesadas ${ }^{21}$. Por su parte, la STJ de 27 de marzo de 2014, asuntos T-56/09 y T-73/09, nos indica que la excesiva duración de un proceso no implica necesariamente la anulación de la decisión que lo concluye. En efecto, el Tribunal señala que «en materia de aplicación de las normas sobre competencia, un plazo cuya duración exceda de lo razonable sólo puede constituir un motivo de anulación de una decisión en la que se constaten infracciones si se demuestra que la violación de este principio ha vulnerado los derechos de defensa de las empresas de que se trate. Fuera de este supuesto especifico, el incumplimiento de la obligación de pronunciarse en un plazo razonable no influye en la validez de los procedimientos administrativos».

Aunque el segundo párrafo del art. 47 CDFUE no haga referencia a esta garantía en términos explícitos, el derecho a la motivación de las resoluciones judiciales puede considerarse un principio insoslayable del derecho a la tutela judicial efectiva ${ }^{22}$.

El Tribunal de Luxemburgo ha hecho referencia al deber de los órganos jurisdiccionales de motivar sus actuaciones en distintas sentencias aclarando algunos aspectos básicos de esta garantía procesal.

Así, en la STJ de 25 de octubre de 2001, asunto C 120/99, la suprema instancia europea pone de relieve la necesidad de que la motivación se adapte a la naturaleza del acto de que se trate y muestre de manera clara e inequívoca el razonamiento de la institución de la que haya emanado dicho acto. Sin embargo, este último requisito no supone para el tribunal el deber de seguir exhaustivamente y uno por uno todos los razonamientos expuestos por las partes en la controversia, pues es incluso admisible una formulación implícita de la motivación siempre que permita a los interesados conocer los fundamentos que justificaron la

20 Así en las SsTJ de 21 de septiembre de 2006, asunto C-105/04 P; de 15 de octubre de 2002, asuntos C-238/99 P, C-244/99 P, C-245/99 P, C-247/99 P, C-250/99 P a C-252/99 P y C-254/99 P; de 30 de septiembre de 2003, asunto T-196/01.

21 Ibídem y además en la STJ de 16 de septiembre de 1999, Partex/Comisión, T-182/96. El propio TEDH ha indicado estos mismos criterios para determinar la excesiva duración de un proceso. Entre otras queremos destacar las SsTEDH de 6 de mayo de 1981, caso Buchbolz c. Alemania; de 13 de julio de 1983, caso Zimmermann y Steiner c. Suiza; de 23 de abril de 1987, caso Erkner y Hofauer c. Austria; de 25 de marzo de 1999, casos Unión Alimentaria Sanders S.A. c. España y Pélissier y Sasi c. Francia; de 12 de mayo de 1999, caso Ledonne c. Italia; de 4 de abril de 2000, caso I.S. c. Eslovaquia; de 4 de abril de 2001, caso Academy Trading Ltd. y otros c. Grecia; de 25 de septiembre de 2001, caso Kizilöz c. Turquía; de 15 de noviembre de 2001, caso Cerin c. Grecia; de 23 de abril de 1998, casos Adolf c. Austria; Süssman c. Alemania; Doustaly c. Francia; de 25 de septiembre de 1998, caso Portington c. Grecia; de 26 de octubre de 2000, caso Kudla c. Polonia. Cfr. Milione, C., El derecho..., ob. cit., pp. 144-150.

22 Vd. en este sentido STEDH de 21 de enero de 1999, caso García Ruiz c. España. 
adopción de las medidas controvertidas y al órgano jurisdiccional competente disponer de los elementos suficientes para ejercer su control ${ }^{23}$.

Finalmente, es interesante analizar la última parte del segundo párrafo del art. 47 CDFUE por el que «toda persona podrá hacerse aconsejar, defender y representar». Dos resoluciones del Tribunal de Luxemburgo destacan, entre otras, en relación a esta garantía. En ambos casos, la Corte europea está llamada a resolver cuestiones de fondo bien distintas, pero estrechamente relacionadas con la necesidad de proteger los derechos de defensa y representación más básicos de las partes. Hablamos de la STJ de 12 de junio de 2014, asunto C-314/13 y la STJ de 26 de junio de 2007, asunto C-305/05.

En la primera resolución, relativa a una solicitud de desbloqueo de fondos para el pago de los honorarios de representación legal, el Tribunal de Luxemburgo evidencia el importante papel desarrollado por la asistencia letrada dentro de los procedimientos judiciales. En efecto, la instancia europea afirma que «el abogado es considerado un colaborador de la justicia, que ba de proporcionar, con plena independencia y para el interés superior de la misma, la asistencia legal que el cliente necesita» ${ }^{24}$, razón por la que una demanda firmada por el propio demandante no puede considerarse suficiente para la interposición de un recurso. Así, interpretando el art. 3.1.b) del Reglamento (CE) n. ${ }^{\circ}$ 765/2006 (del Consejo relativo a la adopción de medidas restrictivas contra el Presidente Lukashenko y determinados funcionarios de Belarús), la Corte europea declara que compete a la autoridad nacional ejercer sus funciones en relación al desbloqueo de fondos para destinarlos exclusivamente al pago de honorarios profesionales razonables y al reembolso de gastos de representación legal, en el respeto de los principios consagrados en el art. 47 CDFUE.

La STJ de 26 de junio de 2007, asunto C-305/05, sin embargo, se ocupa de resolver una cuestión sustancialmente distinta, aunque concerniente al derecho a la asistencia letrada. El asunto gira en torno a la Directiva 91/308/CEE, del Consejo de 10 de junio de $1991^{25}$, por la que incumbía a los abogados ( profesionales independientes del Derecho») el deber de aportar a las autoridades competentes informaciones sobre el blanqueo de capitales conseguidas en el marco de la relación con sus clientes. El Tribunal de Luxemburgo, estimó que la obligación consagrada en el art. $2 b i s$ n. ${ }^{\circ} 5$ de la citada Directiva no constituía una violación de los derechos de defensa y representación legal consagrados en el art. $6 \mathrm{CEDH}$ (y por ende en el art. $47 \mathrm{CDFUE}$ ) puesto que el deber de informar quedaba circunscrito a una serie de actividades de orden financiero, como tales ajenas al ámbito judicial o de preparación de un juicio.

23 SsTJ de 7 de enero de 2004, asuntos C-204/00 P, C-205/00 P C-211/00 P, C-213/00 P, C-217/00 P y C-219/00 P, y en la 19 de junio de 1990, asunto C-213.

24 Una exigencia que se radica no sólo en el art. 47 CDFUE, sino en el mismo Estatuto del Tribunal de Justicia (art. 19) y que respalda una amplia jurisprudencia: STJ de 18 de mayo de 1992, asunto C-155/79; de 14 de septiembre de 2010, asunto C-550/07 P; de 6 de septiembre de 2012, asuntos C-422/11 P y C-423/11 P.

25 En su versión modificada por la Directiva 2001/97/CE del Parlamento y del Consejo, de 4 de diciembre de 2001. 


\section{El derecho a la asistencia jurídica gratuita en el tercer párrafo del art. 47 CDFUE}

El derecho a la asistencia jurídica gratuita constituye una exigencia que completa el principio de representación legal descrito en la última parte del epígrafe anterior, y viene a reforzar la idea de que la asistencia letrada es imprescindible y está desvinculada de las circunstancias económicas de las partes para el desarrollo de determinados juicios que destaquen por su complejidad.

A este respecto, el Praesidium vuelve a hacer mención del CEDH y particularmente de la jurisprudencia del TEDH ${ }^{26}$ para recordar que la razón de fondo de este precepto reside en la necesidad de conceder asistencia jurídica en todas aquellas circunstancias en las que su ausencia pudiera hacer ineficaz la garantía de un recurso efectivo.

El tenor literal del tercer párrafo del art. 47 CDFUE sustancialmente coincide con el del art. 6.3 letra c) $\mathrm{CEDH}$, aunque el primer precepto hace particular hincapié en la falta de recursos económicos y en la necesidad de garantizar la efectividad del acceso a la justicia como condiciones para la prestación gratuita de la asistencia jurídica.

Sin embargo, el precepto consagrado en el Convenio de Roma vincula dicha prestación a la concurrencia de dos requisitos diferentes: en primer lugar, carecer de los medios suficientes para remunerar al propio defensor; en segundo lugar, que «los intereses de la justicia lo exijan».

De los dos supuestos requeridos, el segundo se caracteriza por una formulación dudosa e incierta ${ }^{27}$ que dejaría un amplio margen de apreciación a favor de los Estados. Dicha circunstancia parece ser la causa de la indulgencia mostrada por el TEDH a la hora de detectar violaciones del derecho a la asistencia jurídica gratuita ${ }^{28}$.

No obstante, el Tribunal de Estrasburgo, en distintas resoluciones ${ }^{29}$, ha interpretado el alcance de la expresión «intereses de la justicia», ofreciendo una serie de criterios hermenéuticos y supuestos objetivos útiles para detectar violaciones de ese derecho. Entre ellos cabe destacar, en el ámbito penal, la severidad de la pena potencial, la gravedad de la infracción imputada, la situación personal del imputado y, en general en todos los contextos judiciales, los hechos y circunstancias particulares de cada caso concreto, la importancia que para el demandante

26 Véase la STEDH de 9 de octubre de 1979, caso Airey c. Irlanda.

27 La verificación de la carencia de recursos — principalmente económicos — no representa una tarea problemática, correspondiendo al acusado demostrar esta condición. Véase la STEDH de 25 de septiembre de 1992, caso Croissant c. Alemania.

28 Violaciones que adquieren la sustancia de denegaciones abiertamente arbitrarias de la petición de un abogado de oficio. Véase, por ejemplo, la STEDH de 25 de septiembre de 1992, caso Pahm Hoang c. Francia.

29 SsTEHD de 7 de mayo de 2002, caso McVicar c. Reino Unido; de 16 de julio de 2002, caso P., C. y S. c. Reino Unido; de 15 de febrero 2005, caso Steel y Morris c. Reino Unido. 
tiene el objeto del proceso, la complejidad del Derecho y del procedimiento aplicables, así como la capacidad del demandante de defender eficazmente su causa. Además, el TEDH señala que, en determinadas circunstancias, puede no tenerse en cuenta la situación económica del demandante o la posibilidad de que su recurso prospere ${ }^{30}$.

Cuando el Estado considere legítimo reconocer la asistencia jurídica gratuita, su obligación no se resuelve únicamente con hacerse cargo de la designación de un abogado. En efectos, el TEDH recuerda que el Convenio, hablando de «asistencia» y no de «designación», pretende garantizar la efectividad del derecho en cuestión ${ }^{31}$. Por esta razón, es deber del Estado controlar que la defensa sea asegurada a lo largo de todo el juicio en un sentido real y concreto, conforme a lo que eficazmente establece el preámbulo del $\mathrm{CEDH}^{32}$.

La doctrina del Tribunal de Estrasburgo en esta materia ha sido clave para interpretar el alcance del tercer párrafo del art. 47 CDFUE. Entre todas, lo pone en evidencia la STJ de 22 de diciembre de 2010, asunto C-279/09, que es clave no sólo para definir el alcance de dicho precepto sino, más en general, para entender hasta qué punto se ha producido la incorporación de criterios interpretativos del TEDH por parte del Tribunal de Luxemburgo.

En esa resolución, relativa a la legitimidad del reconocimiento del derecho a la asistencia legal gratuita a una persona jurídica, la suprema instancia europea recuerda que la citada doctrina del Tribunal de Estrasburgo exige dicho reconocimiento en todos aquellos casos en los que su falta pudiera hacer ineficaz la garantía de la tutela judicial efectiva (apartado n. ${ }^{\circ}$ 36). A continuación, interpretando el término «persona» presente en los dos primeros párrafos del art. 47 CDFUE, el TJUE recuerda que dicha expresión se refiere a las personas físicas aunque «desde un punto de vista estrictamente terminológico, no excluye a las personas jurídicas» ${ }^{33}$. Asimismo, la Corte recuerda que la inclusión del derecho a la asistencia gratuita se enmarca en el contexto del Capítulo VI de la Carta,

30 STEDH del caso Steel y Morris c. Reino Unido, antes citada, $§ 62$. Aunque el mismo Tribunal de Estrasburgo, en el caso Monell y Morris c. Reino Unido, STEDH de 2 de marzo de 1987, acuñó otro criterio, definido «valoración de la sostenibilidad de la pretensión», para indicar la oportunidad de negar la asistencia jurídica gratuita en todos aquellos casos en los que la pretensión resulte inadmisible por considerarse contraria a las normas que rigen el procedimiento o porque, simplemente, es reiterativa de algo anteriormente pretendido y desestimado.

31 Véase, por ejemplo, la STEDH de 13 de mayo de 1980, caso Artico c. Italia.

32 Como ha puesto en evidencia el TEDH (Sentencia de 10 de octubre de 2002, caso Czekalla c. Portugal) de esta forma no se dejaría sin protección al justiciable en todas aquellas hipótesis en las que su defensor de oficio no realice propiamente su función, ya sea por una enfermedad, por un impedimento temporal o permanente, o - algo peor - por eludir sus deberes o cumplirlos de manera negligente o superficial. Dichas eventualidades, sobre todo estas últimas, podrían conllevar la responsabilidad del Estado por omisión, a continuación que estas carencias o estas incompetencias resultan manifiestas.

33 Interpretación que quedaría corroborada por la contraposición, existente en la versión alemana de la Carta, entre el término «Person» (empleado en el art. 47 CDFUE) y la palabra «Mensch» (utilizada en los Arts. $1,2,3,6,29,34$ y 35 CDFUE). 
relativo a la Justicia, en el cual se enuncian otros principios que son de perfecta aplicación a las personas jurídicas ${ }^{34}$.

No obstante, el TJUE pone de relieve que el derecho contemplado por el párrafo tercero del art. 47 CDFUE, al igual que para otras garantías contempladas en el mismo precepto, no constituye un derecho absoluto, siendo admisible - y correspondiente a la práctica de los demás Estados miembros_ la existencia de límites a esta garantía.

Así, recordando nuevamente la doctrina del TEDH, el Tribunal de Luxemburgo señala la necesidad de que los procedimientos de concesión de la asistencia legal gratuita, implantados por las legislaciones nacionales, se inspiren en el principio de seguridad jurídica y de no arbitrariedad ${ }^{35}$. Desde esta perspectiva, el TJUE concluye que no posible excluir que el derecho del tercer párrafo del art. 47 CDFUE pueda ser invocado por personas jurídicas. En opinión de la Corte corresponde «al juez nacional comprobar si los requisitos para la concesión de la asistencia jurídica gratuita constituyen una limitación del derecho de acceso a los tribunales que pueda afectar a la propia esencia de este derecho, si persiguen un fin legitimo y si existe una relación razonable de proporcionalidad entre los medios empleados y el fin perseguido."

Por último, merece la pena señalar que a estos mismos criterios interpretativos relativos al derecho a la asistencia letrada se inspira claramente la Directiva 2003/8/ CE del Consejo, de 27 de enero de 2003, destinada a mejorar el acceso a la justicia en los litigios transfronterizos mediante el establecimiento de reglas mínimas comunes relativas a la justicia gratuita para dichos litigios; y más recientemente la Directiva 2013/48/UE del Parlamento Europeo y del Consejo, de 22 de octubre de 2013 , sobre el derecho a la asistencia de letrado en los procesos penales y en los procedimientos relativos a la orden de detención europea, y sobre el derecho a que se informe a un tercero en el momento de la privación de libertad y a comunicarse con terceros y con autoridades consulares durante la privación de libertad.

\section{CONCLUSIONES: EL ALCANCE DE LA CARTA TRAS LAS SSTJ DE 26 DE FEBRERO DE 2013, ASUNTOS C-617/10 Y C-399/11}

Tal como hemos señalado anteriormente, la STJ de 22 de diciembre de 2010, asunto C-279/09, es una clara demostración del importante papel que reviste el

34 A diferencia de lo que ocurre en el Derecho alemán donde dicha garantía procesal adquiere naturaleza de prestación social relacionada con los principios del Estado Social y con el concepto de dignidad humana, razones por las que el Tribunal Constitución Federal ha descartado el reconocimiento del derecho a la asistencia legal gratuita a favor de personas jurídicas. Vd. Sentencia del Bundesverfassungsgericht de 3 de julio de 1973,1 BvR 153/69.

35 SsTEDH de 26 de febrero de 2002, caso Del Sol c. Francia; de 29 de septiembre de 2009, caso Puscasu c. Alemania; de 14 de octubre de 2010, caso Pedro Ramos c. Suiza. 
CEDH y, particularmente, la jurisprudencia del TEDH en la labor hermenéutica realizada por el Tribunal de Luxemburgo sobre la Carta de Niza.

Desde la aprobación del art. 6 TUE, que ha supuesto un fuerte impulso para la política europea en materia de protección de derechos y libertades fundamentales y ha constituido un hito para la legislación de la Unión, la CDFUE ha adquirido la misma dignidad de los demás Tratados, con la misma fuerza vinculante y el mismo valor jurídico (art. 6.1 TUE).

Sin embargo, para poder entender el verdadero alcance de la Carta es necesario interpretar el art. 6 TUE en conexión con el art. 52.3 CDFUE, norma por la que se establece que los derechos contenidos en la Carta que correspondan a los derechos consagrados por el Convenio, gozarán del mismo alcance y del mismo sentido que estos últimos, aunque dicha condición no obste a que el Derecho de la Unión conceda una protección más extensa.

Por lo tanto, las dos normas vienen a determinar un estándar mínimo de protección de los derechos fundamentales en Europa que otorga, en primera instancia, un papel protagonista al Convenio y en términos puramente eventuales un papel incluso más relevante al Derecho de la Unión que, en el interés de la ciudadanía europea, puede sobrepasar los estándares mínimos establecidos por el mismo $\mathrm{CEDH}^{36}$.

Siendo esta la situación tras la aprobación del Tratado de Lisboa, no nos puede sorprender que el TJUE afirmara tajantemente que el art. 52.3 CDFUE exige que el sentido y alcance de los derechos garantizados no queden determinados únicamente por el texto del $\mathrm{CEDH}$, sino también, en particular, por la jurisprudencia del $\mathrm{TEDH}^{37}$.

Sin embargo, más recientemente, la doctrina del TJUE ha conocido una importante evolución que está abriendo nuevos escenarios en el contexto de la protección europea de los derechos.

Así lo demuestra por un lado la STJ de 26 de febrero de 2014, asunto C-617/10 «Hans Akerberg Fransson», con la que el Tribunal de Luxemburgo se preocupa de recordar que el Convenio y la Carta no son lo mismo, no se encuentran en un mismo plano, ni gozan — todavía- de la misma dignidad.

En este sentido, la Corte europea señala que, aunque el párrafo tercero del art. 52 CDFUE, en conjunción con el art. 6.3 TUE, exige dar a los derechos contenidos en la Carta el mismo sentido y alcance de los derechos correspondientes consagrados en el Convenio, "éste no constituye un instrumento jurídico integrado formalmente en el ordenamiento jurídico de la Unión», dado que ésta no se ha adherido a él.

36 García Roca, F. J., («La interpretación constitucional de una declaración internacional, el Convenio Europeo de Derechos Humanos, y bases para una globalización de los derechos», Revista Iberoamericana de Derecho Procesal Constitucional, n. ${ }^{\circ}$ 5, 2006, pp. 139-182) habla del art. 52.3 CDFUE como de una «cláusula de remisión» que otorga al Convenio una protección «necesaria» y «subsidiaria». Así, cit. por FAGGIANI, V., («El derecho...», ob. cit., p. 15 y 16) que nos recuerda cómo la Carta está destinada a absorber a fuentes tales como el Convenio.

37 Así en la citada la STJ de 22 de diciembre de 2010, asunto C-279/09, (apartado n. ${ }^{\circ} 35$ ). 
Se trata, en un cierto sentido, de afirmaciones que anticipan las conclusiones del mismo Tribunal de Justicia recogidas en el Dictamen 2/13, de 18 de diciembre de 2014, en el que la Corte cuestiona firmemente la posibilidad de adhesión de la UE al CEDH sobre la base de argumentos complejos y — sin embargo- criticables $^{38}$.

Por otra parte, mientras el Derecho de la Unión no regula la relación entre el CEDH y los ordenamientos jurídicos nacionales, ni indica qué criterios cabe adoptar en caso de conflicto entre los derechos que garantiza el Convenio y una norma de Derecho nacional ${ }^{39}$, sí existen criterios para resolver posibles conflictos entre legislaciones nacionales y CDFUE y que consisten en el principio del «efecto directo» y de «supremacía del Derecho de la Unión» ${ }^{40}$.

No obstante, el verdadero punto de inflexión en la doctrina del TJUE lo encontramos en el apartado n. 29 de la Sentencia Fransson, es decir en un punto en el que ese Tribunal se encamina por «una zona de grises», intentando dar respuesta a una hipótesis ulterior: la de un juez nacional llamado a enjuiciar la conformidad con los derechos fundamentales de una medida nacional que aplica el Derecho de la Unión, cuando dicha legislación europea no determina, en todos sus aspectos, la acción de los Estados miembros.

38 Como sabemos, la adhesión tendría como efecto el de someter la UE al control de una jurisdicción (la del TEDH) que en principio no le pertenece. Así, la Unión se encontraría en la misma condición de los demás Estados miembros, llamada como ellos mismos a responder de la tutela de los derechos consagrados en el Convenio. Asimismo, otros efectos serían el de ofrecer la posibilidad a ciudadanos ajenos a la UE de recurrir ante el Tribunal de Estrasburgo actos jurídicos de la Unión o permitir a la Unión de formar parte del pleno del TEDH con el nombramiento de un propio magistrado. Los argumentos que esgrime el Tribunal de Luxemburgo en su dictamen para argumentar la inoportunidad de la adhesión de la Unión al CEDH versan sobre el principio de autonomía del Derecho de la Unión; sobre el art. 344 TUE, en virtud del que «los Estados miembros se comprometen a no someter las controversias relativas a la interpretación o aplicación de los Tratados a un procedimiento de solución distinto de los previstos en los mismos»; sobre los mecanismos de intervención previa del Tribunal de Luxemburgo; sobre el control jurisdiccional de la Política Exterior y de Seguridad común; etc. Sobre este tema, señalamos entre otros MARTín y PÉREZ de NANCLARES, J., «El TJUE pierde el rumbo en el dictamen 2/13: ¿merece todavía la pena la adhesión de la UE al CEDH?», en Revista de Derecho Comunitario Europeo, año n. ${ }^{\circ} 19$, n. ${ }^{\circ}$ 52, 2015, pp. 825-869; LlOpis NADAL, P., «La necesidad procesal de la adhesión de la Unión Europea al CEDH: un asunto que continúa pendiente tras el dictamen 2/13 del TJUE», en Revista electrónica de estudios internacionales (REEI), n. ${ }^{\circ}$ 29, 2015; GONZÁLEZ VEGA, J. A., «La «teoría del big bang»o la creciente distancia entre Luxemburgo y Estrasburgo: (Comentarios al Dictamen 2/13, del Tribunal de Justicia, de 18 de diciembre de 2014 sobre la adhesión de la unión Europea al Convenio Europeo de Derechos Humanos)», en La Ley Unión Europea, n. ${ }^{\circ}$ 25, 2015, pp. 17-50; GonZÁlEZ HerrerA, D., «Dictamen 2/13 del Tribunal de Justicia de la Unión Europea (Pleno): Adhesión de la Unión Europea al Convenio Europeo de Derechos Humanos», en AIS — Ars Iuris Salmanticensis, Revista europea e iberoamericana de pensamiento y análisis de derecho, ciencia política y criminología, Vol. 3, n. ${ }^{\circ}$ 1, 2015, pp. 367-369; Cortés Martín, J. M., «Sobre el dictamen del TJUE $n .^{\circ} 2 / 13$, relativo a la adhesión al CEDH, la tutela judicial efectiva en la PESC y la unión de derecho", en Unión Europea Aranzadi, n. ${ }^{\circ}$ 8-9, 2015, pp. 67-92.

39 Apartado n. ${ }^{\circ} 44$. Vd. STJ de 24 de abril de 2012, C-571/10, apartado n. ${ }^{\circ} 62$.

40 Según el TJUE (apartado n. ${ }^{\circ} 45$ ) «el órgano jurisdiccional nacional encargado de aplicar, en el marco de su competencia, las disposiciones del Derecho de la Unión está obligado a garantizar la plena eficacia de estas normas dejando inaplicada de oficio, en caso de necesidad, cualquier disposición contraria de la legislación nacional, incluso posterior, sin solicitar o esperar su previa derogación por el legislador o mediante cualquier otro procedimiento constitucional.» Vd. SsTJ de 9 de marzo de 1978, asunto C-106/77; de 19 de noviembre de 2009, asunto C-314/08; de 22 de junio de 2010, asuntos C-188/10 y C-189/10. 
La respuesta que elabora el Tribunal de Luxemburgo constituye una solución de compromiso que consiste en facultar a las autoridades y tribunales nacionales para que apliquen los estándares nacionales de protección de los derechos fundamentales, a condición de que «esa aplicación no afecte al nivel de protección previsto por la Carta, según su interpretación por el Tribunal de Justicia, ni a la primacía, la unidad y la efectividad del Derecho de la Unión.»

Como señalan Gordillo Pérez y Tapia Trueba, esta resolución constituye un ejemplo de armonización «escasamente intensa» en materia de protección de derechos que, por otra parte, deja sin solución un problema ulterior, como es el relativo al valor de la Carta respecto a los actos de los Estados miembros accidentalmente conectados con el Derecho de la Unión ${ }^{41}$.

La doctrina del TJUE ha conocido otro punto de inflexión en el mismo día en el que esta instancia aprobó la Sentencia Fransson. Nos referimos a la célebre STJ de 26 de febrero de 2013, asunto C-399/11 «Stefano Melloni», con la que el Tribunal de Luxemburgo, por vez primera, interviene para determinar el alcance interpretativo del art. 53 CDFUE, relativo al nivel de protección de la Carta.

El TJUE se encuentra llamado a responder a tres cuestiones prejudiciales sobre el sentido y el alcance del art. 4bis.1 de la Decisión marco 2009/299/JAI del Consejo, de 26 de febrero de 2009, relativo a la orden de detención europea («euroorden» $)^{42}$. En una exposición de argumentos que ha sido tachada por algunos autores como excesivamente escueta ${ }^{43}$, el Tribunal de Luxemburgo defiende

41 Gordillo Perez, L. I. y Tapia Trueba, A., «Diálogos, monólogos y tertulias. Reflexiones a propósito del caso Melloni», en Revista de Derecho Constitucional Europeo, n. ${ }^{\circ}$ 22, Julio-Diciembre 2014. Al respecto, los autores hacen referencia a una respuesta negativa a este último dilema, ofrecida por el Tribunal Constitucional alemán. Cfr. J.H. Reestman Y L. Besselink, «After Åkerberg Fransson and Melloni», en European Constitutional Law Review, Vol. 9, n. ${ }^{\circ}$ 2, 2013, pp. 169-175, en especial p. 171.

42 En realidad, la citada resolución destaca además, desde la perspectiva española, por resolver las primeras cuestiones prejudiciales planteadas por el Tribunal Constitucional español, en relación a la citada Decisión marco 2009/299/JAI del Consejo, de 26 de febrero de 2009. En síntesis, las preguntas planteadas consistían en lo siguiente: 1) conocer si el art. 4 bis. 1 de la citada Decisión impide a las autoridades judiciales nacionales someter la ejecución de una euroorden a la condición de que la condena en cuestión pueda ser revisada; 2) si el art. 4bis. 1 de la citada Decisión es compatible con las exigencias de los Arts. 47 y 48 CDFUE; 3) si el art. 53 CDFUE, interpretado con los Arts. 47 y 48 CDFUE, permite a un Estado miembro condicionar la ejecución de una euroorden a que la condena pueda ser revisada para así otorgar a esos derechos un mayor nivel de protección que el que se deriva del Derecho de la Unión Europea, a fin de evitar una interpretación limitativa o lesiva de un derecho fundamental reconocido por la Constitución de ese Estado miembro

43 Señalamos entre otros Salinas Alcega, S., «Sentencia del Tribunal de Justicia (Gran Sala) de 26 de febrero de 2013 - Stefano Melloni y Ministerio fiscal (As. C-399/11) — Ejecución de orden de detención europea emitida contra una persona condenada en rebeldía», Unión Europea Aranzadi, 2014, n. ${ }^{\circ}$ 2, pp.49-52; Pollicino, O., «From Partial to Full Dialogue with Luxembourg: The Last Cooperative Step of the Italian Constitutional Court», European Constitutional Law Review, Vol. 10, 2014, pp. 143-153; Ripol Carulla, S., y Ugartemendía Eceizabarrena, J.I, «La euroorden ante la tutela de los derechos fundamentales. Algunas cuestiones de soberanía iusfundamental (A propósito de la STJ Melloni, de 26 de febrero de 2013, C-399/11», Revista española de Derecho Europeo, Vol. 46, 2013, pp. 151-198; MARTín RodríGuez, P.J., «Sentencia 26/2014, de 13 de febrero, en el recurso de amparo 6922/2008 promovido por Don Stefano Melloni», Revista de Derecho Comunitario Europeo, Vol. 48/1, 2014, pp. 603-622. 
rotundamente la supremacía del Derecho de la Unión ${ }^{44}$, por encima de los sistemas constitucionales de protección de los derechos fundamentales de los Estados miembros, puesto que "la invocación por un Estado miembro de las disposiciones del Derecho nacional, aun si son de rango constitucional, no puede afectar a la eficacia del Derecho de la Unión en el territorio de ese Estado. ${ }^{45}$

Las Sentencias Fransson y Melloni, que han ocupado - y siguen haciéndolola atención de una amplia parte de la doctrina, nos indican cuál está siendo el camino que, en el ámbito de sus funciones, el Tribunal de Luxemburgo ha emprendido para alcanzar la meta de la construcción de un sistema de protección de los derechos fundamentales en ámbito Europeo.

Del análisis de la jurisprudencia del TJUE relativa al art. 47 CDFUE se desprende una lenta e inexorable evolución de su doctrina hacia una configuración que antepone la afirmación de la supremacía del Derecho de la Unión por encima de los mecanismos de protección propios de cada Estado miembro. Indudablemente es un camino que plantea verdaderos retos adaptativos para las legislaciones nacionales, y sobre todo para sus ordenamientos constitucionales, destinados a ceder terreno ante la necesidad de construir un modelo de integración fundado en la preeminencia de los derechos ubicados en el máximo nivel normativo de la Unión.

Se trata de un interesante escenario que se halla en constante desarrollo y se caracteriza por el «dialogo judicial» ${ }^{46}$ que protagonizan el TJUE, el TEDH y los Tribunales Constitucionales nacionales. Como hemos visto, los efectos del Dictamen 2/13 del Tribunal de Luxemburgo parecen alejar del horizonte las posibilidades de una pronta adhesión de la UE al CEDH, en cumplimiento de esa promesa consagrada en el art. 6.2 TUE. Cuándo se escribirá el enésimo capítulo de este relato todavía no es posible saberlo.

$$
* * *
$$

TITLE: The interpretation of the Art. 47 CFREU carried out by the Luxembourg Court as an expression of the hermeneutics for the establishment of a European standard of protection of fundamental rights

ABSTRACT: Since the entry into force of the Treaty of Lisbon, the Charter of Fundamental Rights of the European Union (CFREU) has acquired an unquestionable relevance in its material scope. The

44 Incluso cuando ese Derecho deriva de un acto legislativo secundario (una «Decisión») que no ha visto la participación del órgano depositario de la voluntad democrática de la Unión (el Parlamento).

45 Todo ello, con la voluntad de enfatizar la importancia de «facilitar y acelerar la cooperación judicial de cara a la consecución del objetivo atribuido a la Unión de llegar a ser un espacio de libertad, seguridad y justicia basado en el grado de confianza elevado que debe existir entre Estados miembros», el TJUE niega al juez nacional la posibilidad de supeditar la ejecución de una euroorden a que la condena que la sustenta pueda ser revisada en el país requirente, puesto que "no se produce una vulneración del derecho a un proceso equitativo, aun si el interesado no ba comparecido en el juicio, cuando haya sido informado de la fecha y del lugar del juicio o haya sido defendido por un letrado al que haya conferido mandato a ese efecto». Apartados n. 37 y 49.

46 Bustos Gisbert, R., «XV Proposiciones generales para una teoría de los diálogos judiciales», en Revista Española de Derecho Constitucional, 2012, n. ${ }^{\circ}$ 95, pp. 13-63. 
Luxembourg Court, as ultimate interpreter of the Charter, intervenes to define the extent of its precepts, establishing a European standard of protection of fundamental rights. This paper describes this evolution, taking into consideration the most relevant resolutions from the Luxembourg Court on the art. 47 CFREU, which establishes the right to an effective remedy and to a fair trial.

Resumen: Desde la entrada en vigor del Tratado de Lisboa, la Carta de los Derechos Fundamentales de la Unión Europea (CDFUE) ha adquirido una relevancia incuestionable en su ámbito material. El Tribunal de Luxemburgo, en calidad de supremo intérprete de la Carta, interviene para definir el alcance de sus preceptos, construyendo con sus sentencias un verdadero estándar de protección de los derechos en seno a la Unión. Este estudio pone de manifiesto esta evolución a partir del análisis las resoluciones más relevantes del Tribunal de Luxemburgo en relación al art. 47 (CDFUE) por el que se consagra el derecho a la tutela judicial efectiva y a un juez imparcial.

Key words: Protection, Rights, Europe, Fair, Trial, Court.

Palabras clave: Protección, Derechos, Europa, Justo, Tribunal.

FECHA DE RECEPCIÓN: 15.10.2016

FECHA DE ACEPTACIÓN: 01.02.2017 